\title{
Towards continuous glucose monitoring: in vivo evaluation of a miniaturized glucose sensor implanted for several days in rat subcutaneous tissue
}

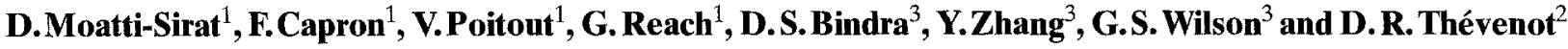 \\ ${ }^{1}$ INSERM U 341, Service de Diabétologie, Hôtel-Dieu, Paris, ${ }^{2}$ LABAM, University Paris Val de Marne, Créteil, France, \\ ${ }^{3}$ Department of Chemistry, University of Kansas, Lawrence, Kansas, USA
}

\begin{abstract}
Summary. A miniaturized amperometric, enzymatic, glucose sensor (outer diameter $0.45 \mathrm{~mm}$ ) was evaluated after implantation in the subcutaneous tissue of normal rats. A simple experimental procedure was designed for the long-term assessment of the sensor's function which was performed by recording the current during an intraperitoneal glucose load. The sensor was calibrated by accounting for the increase in the current during the concomitant increase in plasma glucose concentration, determined in blood sampled at the tail vein. This made it possible to estimate the glucose concentration in subcutaneous tissue. During the glucose load, the change in subcutaneous glucose concentration followed that in blood with a lag time consistently shorter than $5 \mathrm{~min}$. The estimations of subcutaneous glucose concentration during these tests were compared to the concomitant plasma glucose concentrations by using a grid analysis. Three days after implantation ( $n=6$ experiments), 79 estimations were con-
\end{abstract}

sidered accurate, except for five which were in the acceptable zone. Ten days after implantation ( $n=5$ experiments), 101 estimations were accurate, except for one value, which was still acceptable. The sensitivity was around $0.5 \mathrm{nA}$. $\mathrm{mmol}^{-1} \cdot \mathrm{l}^{-1}$ on day 3 and day 10 . A longitudinal study on seven sensors tested on different days demonstrated a relative stability of the sensor's sensitivity. Finally, histological examination of the zone around the implantation site revealed a fibrotic reaction containing neocapillaries, which could explain the fast response of the sensor to glucose observed in vivo, even on day 10 . We conclude that this miniaturized glucose sensor, whose size makes it easily implanted, works for at least ten days after implantation into rat subcutaneous tissue.

Key words: Glucose sensor, subcutaneous tissue.
The aim of a glucose sensor is to provide an accurate continuous measurement of in vivo glucose concentrations. Its potential use for the treatment of Type 1 (insulin-dependent) diabetes mellitus includes the possibility of continuous glucose monitoring, the development of an alarm device for detecting hypoglycaemia or ultimately part of a closed-loop insulin delivery system [1]. Due to the potential hazards if the sensor were implanted in the vascular bed [2], most of the studies have focused on the development of needle-type glucose sensors which, implanted in the subcutaneous tissue, can be easily removed and replaced by the patient [3-11]. Indeed the glucose concentration in subcutaneous tissue closely follows the plasma glucose concentration under stationary conditions [12]. Moreover, the possibility of using subcutaneous glucose concentrations as a signal to monitor blood glucose with a closed-loop insulin delivery system has been clearly established [13]. Development of a needle-type glucose sensor as a step towards the achievement of a clinically useful device requires two further advances: its miniaturization and improvement of its lifespan. Our laboratories have developed a sensor whose size (outer diameter less than $0.5 \mathrm{~mm}$ ) makes it easily implanted into the subcutaneous tissue. This sensor was evaluated after implantation into the subcutaneous tissue of normal rats, for up to ten days.

\section{Materials and methods}

\section{Miniaturized sensor}

The sensor consisted of a platinum-iridium wire coated with teflon $(0.25 \mathrm{~mm}$ outer diameter), except for a $2 \mathrm{~mm}$ cavity near its extremity, where glucose oxidase was immobilized on cellulose acetate, reticulated with glutaraldehyde, and covered by a polyurethane layer. The cathode consisted of an $\mathrm{Ag} / \mathrm{AgCl}$ wire, wrapped tightly around the teflon coated wire. The external diameter of the glucose sensor was therefore $0.45 \mathrm{~mm}$ (Fig. 1). The sensor and its in vitro characterization have been described elsewhere [14]. The in vitro characteristics of the 11 sensors used in this study, determined in phosphate buffer at $37^{\circ} \mathrm{C}$ before implantation, are shown in Table 1. 




Fig. 1. Miniaturized glucose sensor

Sensors were sterilized by dipping them into thimerosal $2.5 \%$ thiomersal, Sigma, St. Louis, Mo., USA, [11].

\section{Experimental procedure for the long-term evaluation of the sensor}

A simple experimental procedure was used for the long-term assessment of the sensor: the sensor was implanted under halothane anaesthesia into the interscapular subcutaneous tissue of overnight-fasted male normal Wistar rats (250-300 g body weight), through a 16 gauge cannula. The cannula was then removed, leaving the sensor in place secured with adhesive plaster. Between the tests which are described below, the animals were left free-moving in their cages, without polarization of the sensor.

For the recording of the current, the sensor was connected to an amperometric unit (PRG-DEL, Tacussel Electronique, Villeurbanne, France). A run-in period ( 2 to $6 \mathrm{~h}$ ) was required to obtain a stable current before performing the glucose test, consisting of an intraperitoneal injection of glucose $(30 \%$ solution, $1.0 \mathrm{~g} / \mathrm{kg}$ body weight, or $1.2 \mathrm{~g} / \mathrm{kg}$ if plasma glucose was lower than $5 \mathrm{mmol} / \mathrm{l})$. Plasma glucose concentration was determined in blood from a tail vein sample with a heparinized Pasteur pipette, at $5 \mathrm{~min}$ intervals. A Beckman analyser was used for glucose assay. Eleven different rats were used, each implanted with a different sensor. In seven cases, the tests were performed on different days after implantation (up to 10 days in one rat). In this first set of experiments, the cause for experiment termination was the removal of the sensor by the animal. It was, nevertheless, possible to recognize the sensor implantation site which was sampled for histological examination. In four additional cases, the glucose test was only performed on day 10 , the animal being killed after the test. In these cases, the implantation area was fixed with the sensor in Bouin's solution for histological examination. After fixation (10-12 h) the sensor was removed, then longitudinal and transverse slices of specimen were processed for routine histological study in paraffin sections. Thus, we will present the figures obtained on day $3-4(n=6)$, on day $10(n=5)$ following the implantation, and a longitudinal study of the sensor response evaluated on different days $(n=7)$.

\section{Calculation of the in vivo characteristics of the sensor and data analysis}

The in vivo characteristics (sensitivity, extrapolated background current) were determined during an intraperitoneal glucose load. Plasma glucose increased to a plateau, whose duration was usually at least $10 \mathrm{~min}$, long enough to establish equilibration between plasma and subcutaneous glucose concentrations [14]. A two-point calibration procedure previously described [15] was used to transform the recorded current (expressed in $\mathrm{nA}$ ) into an estimation of the glucose concentration in subcutaneous tissue (expressed in $\mathrm{mmol} / \mathrm{l}$ ): This procedure takes into account the plasma glucose values (in $\mathrm{mmol} / \mathrm{l}$ ) and the corresponding current levels (in $\mathrm{nA}$ ) in the basal state and at the peak reached during the glucose load. From these values it was possible to calculate, for each individual experiment, an in vivo sensitivity coefficient $\left(\mathrm{SC}\right.$, in $\mathrm{nA} \cdot \mathrm{mmol}^{-1} \cdot \mathrm{l}^{-1}$ ) and an extrapolated background current (current in absence of glucose: $I_{O}$, in $n A$ ). The subcutaneous glucose concentration (SCG) was calculated from the current and the in vivo parameters, according to the equation: $\mathrm{SCG}=\left[\mathrm{I}(\mathrm{t})-\mathrm{I}_{\mathrm{O}}\right] / \mathrm{SC}$.

\section{Statistical analysis}

A statistical study (regression equation, correlation coefficient) is insufficient for evaluating the accuracy of the glucose concentrations determined from the signal of the sensor, since in addition, examination of clinical significance, taking into account the range of blood glucose concentrations currently observed in diabetes practice, is required. Thus, we supplemented the usual statistical methodology by using the "error grid analysis", proposed by Clarke et al. [16], to evaluate the clinical accuracy of various monitoring systems of blood glucose. This grid is divided into five zones, corresponding on a clinical basis to different degrees of accuracy of glucose estimations. Briefly, values of glucose concentration in zone $A$ are accurate, in zone $\mathrm{B}$, acceptable, and in zones $\mathrm{C}, \mathrm{D}, \mathrm{E}$, unacceptable because the results would lead to inaccurate and clinically dangerous treatment decisions. This analytical procedure was applied to the data collected during intraperitoneal tests performed at a day 3 and $4(n=6)$ or at day $10(n=5)$ : the estimation of the subcutaneous glucose concentration was plotted against the concomitant plasma glucose concentration. The basal and peak glucose values used for the determination of the sensor in vivo parameters were neither included in this analysis nor in the calculation of regression equation and correlation coefficient, since, by mathematical construction, they are identical to the subcutaneous glucose values.

\section{Results}

Figure 2 presents the data (mean \pm SEM) for the six experiments (six different animals with a different sensor) performed on day $3(n=5)$ or day $4(n=1)$. The run-in period (the 2 to $6 \mathrm{~h}$ after connection of the sensor to the amperometric unit necessary to obtain a stable current) is not represented. Its duration was not influenced by the duration (in days) of implantation. Following the glucose injection, plasma glucose increased from $4.6 \pm 0.7 \mathrm{mmol} / 1$ to a peak value of $10.8 \pm 0.3 \mathrm{mmol} / \mathrm{l}$. It then decreased

Table 1. In vitro characteristics of the sensors before implantation

\begin{tabular}{lllll}
\hline & $\begin{array}{l}\Delta \mathrm{U} / \Delta \mathrm{C}^{\mathrm{a}} \\
\left(\mathrm{nA} \cdot \mathrm{mmol}^{-1} \cdot \mathrm{1}^{-1}\right)\end{array}$ & $\begin{array}{l}\text { Linearity range } \\
(\mathrm{mmol} / \mathrm{l})\end{array}$ & $\begin{array}{l}\mathrm{Io}^{\mathrm{b}} \\
(\mathrm{nA})\end{array}$ & $\begin{array}{l}\mathrm{t} 90 \%^{\mathrm{c}} \\
(\mathrm{s})\end{array}$ \\
\hline Mean & 1.72 & 22 & 1.9 & 190 \\
SEM & 0.17 & 2 & 0.4 & 40 \\
\hline
\end{tabular}

mean $\pm \mathrm{SEM}, n=11$

a $\Delta \mathrm{I} / \Delta \mathrm{C}$, in vivo sensitivity coefficient;

b Io, extrapolated background current (glucose concentration $=0 \mathrm{mmol} / \mathrm{l})$;

c $\mathrm{t} 90 \%$, time until $90 \%$ of the final steady-state current is reached after switching the sensor from 0 to $5 \mathrm{mmol} / \mathrm{lg}$ glucose-containing solutions 

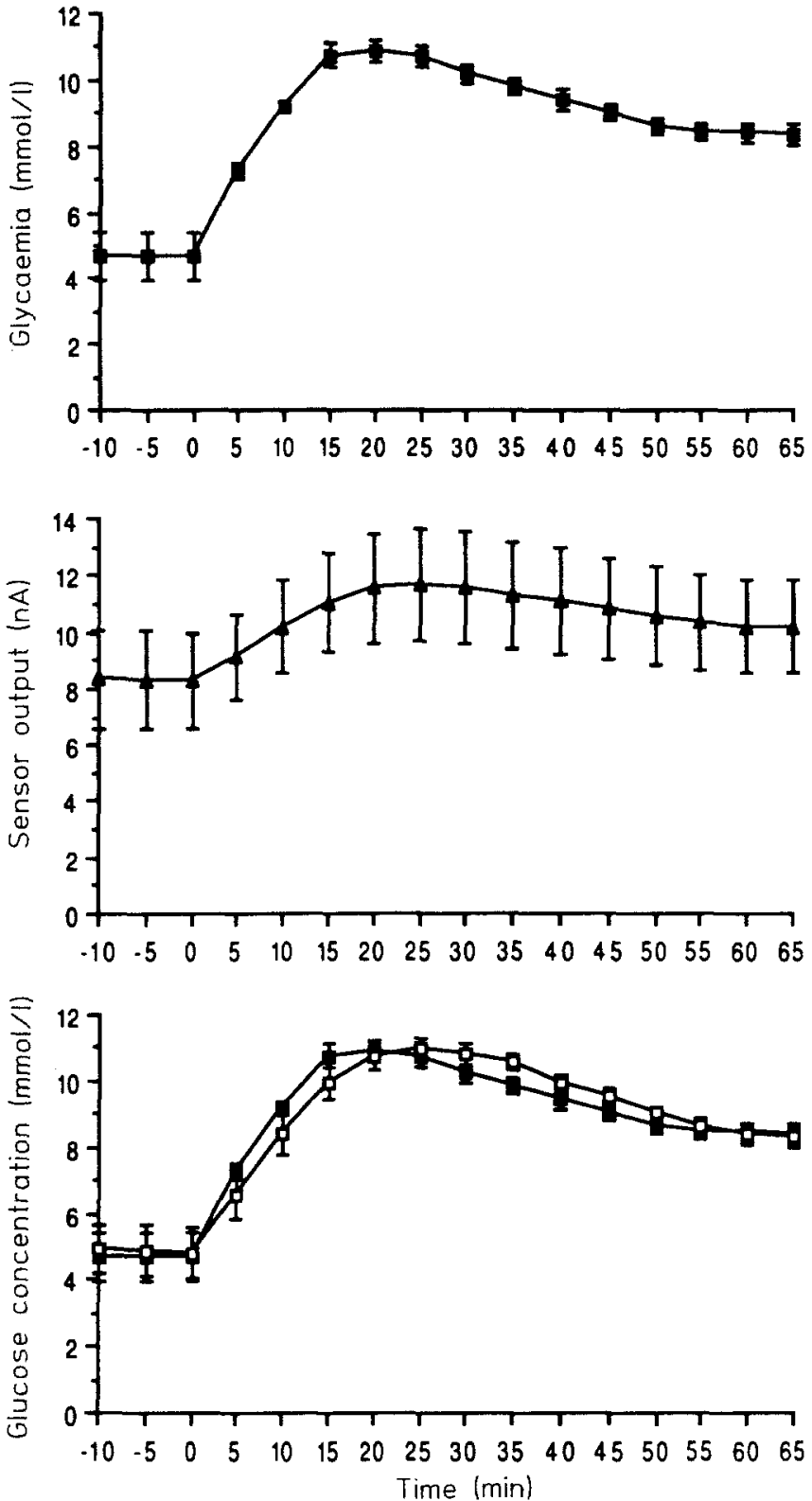

Fig. 2. Means \pm SEM of six experiments performed at day 3 or 4 after sensor implantation. Upper panel: plasma glucose concentration ( $\mathbf{0}$ ); middle panel: simultaneous sensor output $(\boldsymbol{A})$, lower panel: plasma glucose concentration ( $\mathbf{a}$ ) and estimated subcutaneous glucose concentration ( $\square$ )

slowly after a $10 \mathrm{~min}$ plateau to reach a new stable value of $9.0 \pm 0.2 \mathrm{mmol} / 1$ at $45 \mathrm{~min}$. In the same time interval, the current values, depending on the characteristics of each sensor, rose from $8.3 \pm 1.7 \mathrm{nA}$ to $11.7 \pm 2.0 \mathrm{nA}$ and then decreased to $10.0 \pm 1.7 \mathrm{nA}$. The in vivo sensitivity coefficient and the background current, calculated for each experiment from the initial and peak values of glycaemia and current, were $0.54 \pm 0.08 \mathrm{nA} \cdot \mathrm{mmol}^{-1} \cdot \mathrm{l}^{-1}$ and $5.8 \pm 1.4 \mathrm{nA}$, respectively. The sensitivity was significantly lower in vivo than that observed in vitro for the same sensors $\left(1.82 \pm 0.29 \mathrm{nA} \cdot \mathrm{mmol}^{-1} \cdot 1^{-1}, p<0.005\right)$, (Fig. 3, left panel). Subcutaneous glucose concentrations, taking into account the individual in vivo parameters, are represented on the lower panel of Figure 2 with the plasma glucose

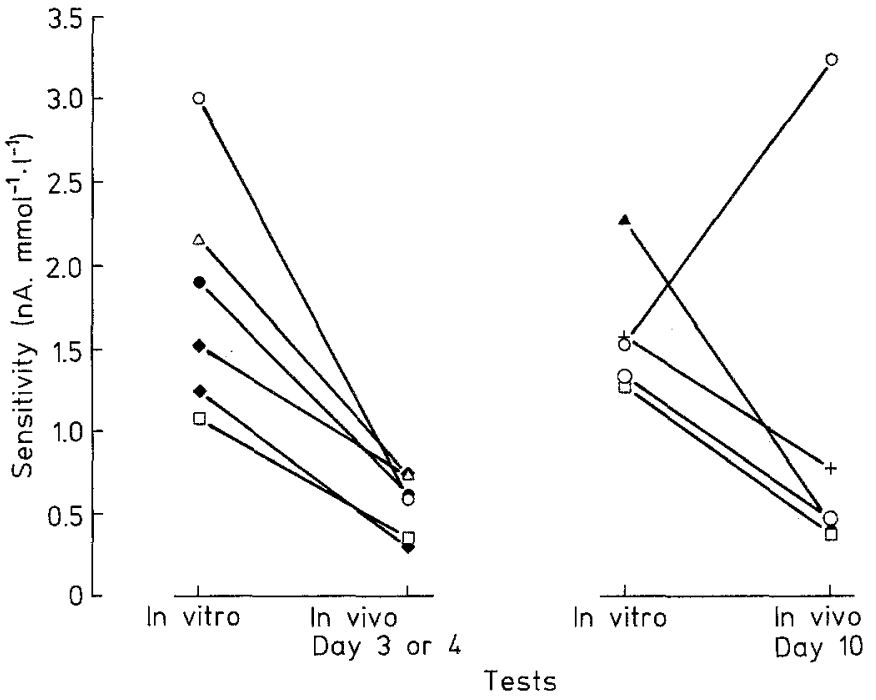

Fig.3. Individual values of the in vitro sensitivity before implantation and the corresponding in vivo sensitivity on day 3-4 (left panel) or day 10 (right panel) after implantation, determined for each sensor

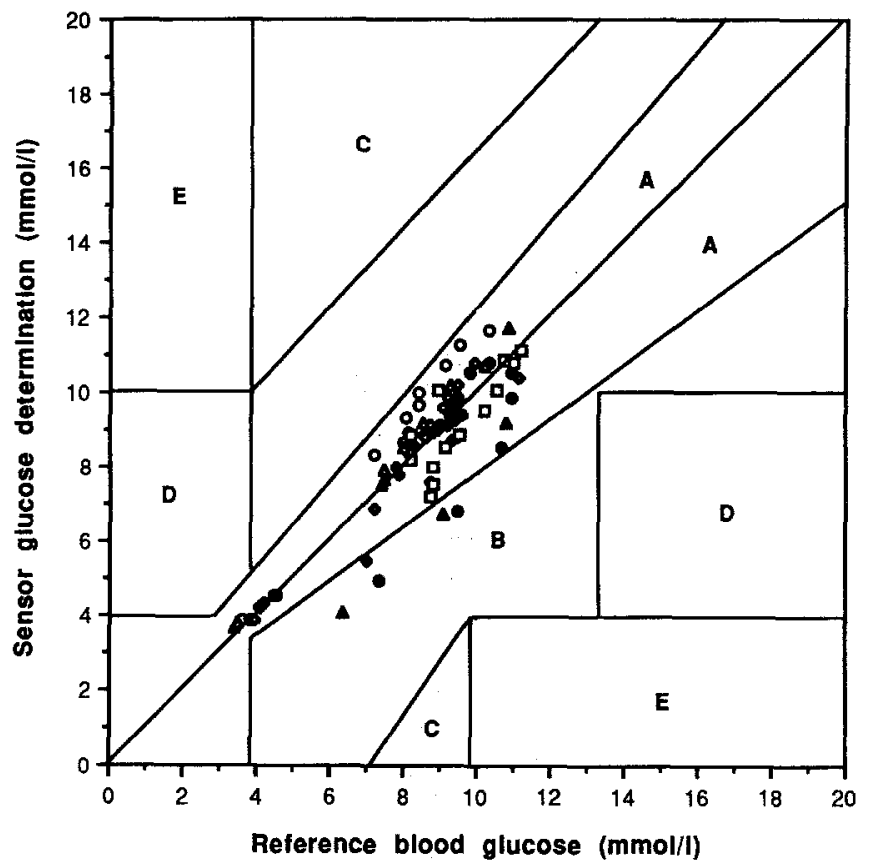

Fig.4. Error grid analysis for estimation of the accuracy of sensor generated blood glucose values, three or four days after implantation. Zone A: clinically accurate; zone B: acceptable values; zones C, $D, E$ : inaccurate values. Each sensor is represented by a different symbol

concentration curve. The lag between the two curves was always shorter than $5 \mathrm{~min}$. Thus, the peak in plasma glucose and in subcutaneous glucose concentrations was observed respectively at $22 \pm 3 \mathrm{~min}$ and $25 \pm 2 \mathrm{~min}$. It must be stressed that no drift in the sensor signal was observed over the duration of these experiments, since subcutaneous glucose concentrations determined at the end of the experiment from the parameters calculated at its beginning were strictly identical with plasma glucose concentrations $(8.4 \pm 0.3 \mathrm{mmol} / \mathrm{l})$. The correlation between the 79 values of glycaemia and the 79 values estimated from 

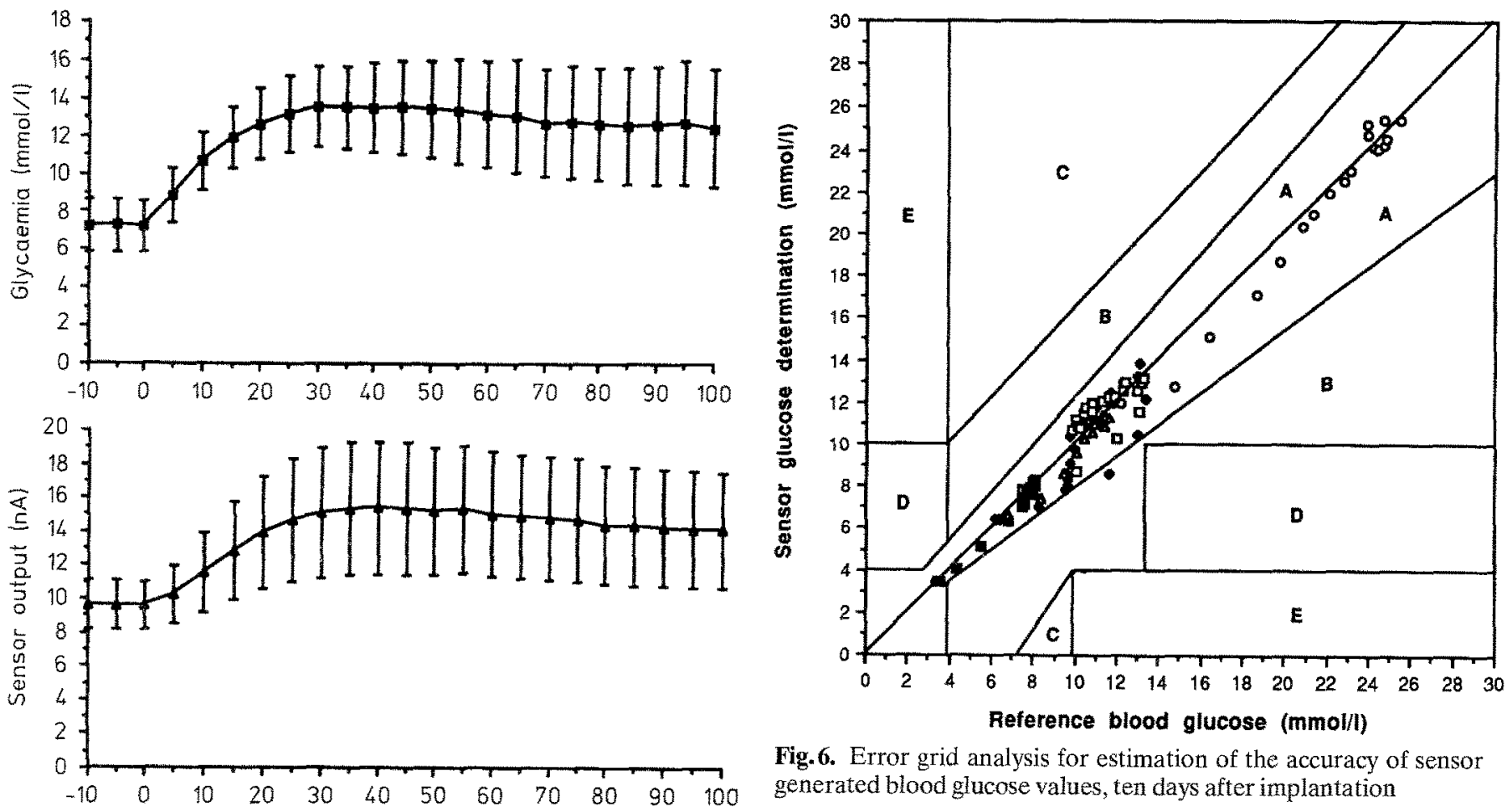

Fig. 6. Error grid analysis for estimation of the accuracy of sensor generated blood glucose values, ten days after implantation

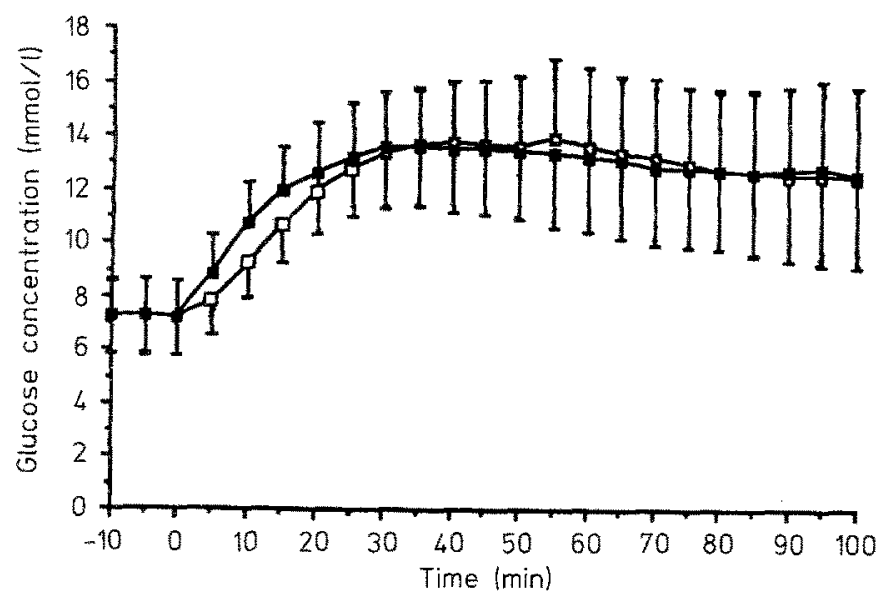

Fig.5. Mean \pm SEM of five experiments performed at day 10 after sensor implantation. Upper panel: plasma glucose concentration ( $)$; middle panel: simultaneous sensor output $(\boldsymbol{A})$; lower panel: plasma glucose concentration ( ) and estimated subcutaneous glucose concentration $(\square)$

the signal of the sensor was $y=0.97 x+0.22 \mathrm{mmol} / \mathrm{l}$, $r=0.91, p<0.001$. Analysis of these results through the error grid analysis proposed by Clarke yielded 74 values $(93.6 \%)$ in zone $\mathrm{A}$ and five values $(6.3 \%)$ in zone B (Fig.4).

Figure 5 represents sensor response obtained during a glucose test performed on day 10 after implantation $(n=5)$. It illustrates the rapid increase in the signal after the glucose injection which was observed in all cases within 2 min. Plasma glucose concentration measured and subcutaneous glucose concentrations estimated from the signal are represented. In these experiments also, subcutaneous glucose concentration determined at the end of the experiment from the parameters calculated at its be-

ginning was identical to the concomitant plasma glucose concentration. After the glucose injection, the signal began to increase with a short lag time $(2.0 \pm 0.5 \mathrm{~min}$, $n=5$ ). The correlation at day 10 , between the values of glycaemia and the simultaneous estimates of subcutaneous glucose concentration $(n=101)$, was $y=0.99 x$ $-0.16 \mathrm{mmol} / \mathrm{l}, r=0.99, p<0.001$. Analysing these results through the error grid analysis indicated that all values were in zone $A$, except one value present in zone $B$ near the border of zone A (Fig. 6).

The in vivo background current was $4.2 \pm 0.48$ $\mathrm{nA}$. Here again, the in vivo sensitivity $(1.05 \pm 0.55 \mathrm{nA}$. mmol $\left.{ }^{-1} \cdot l^{-1}\right)$ was lower than that observed in vitro $\left(1.59 \pm 0.18 \mathrm{nA} \cdot \mathrm{mmol}^{-1} \cdot 1^{-1}\right)$, except for one sensor (Fig. 3, right panel). Together, the four other sensors yield in vitro and in vivo sensitivities of $1.96 \pm 0.30$ and $0.60 \pm 0.23 \mathrm{nA} \cdot \mathrm{mmol}^{-1} \cdot 1^{-1}$, respectively. These figures were similar to those observed with the sensors investigated at day 3 .

Figure 7 represents the follow-up study of one sensor implanted for 5 days in a rat, the glucose test being performed on days $1,2,3$, and 5 . Plasma glucose concentration and the current are represented. Figure 8 represents a longitudinal study of the sensor sensitivity. The results of seven experiments are shown, the sensors being implanted for up to ten days. Except for one sensor, for which a major increase in sensitivity was observed from day 5 , and whose sensitivity on day 10 is shown in Figure 3, this figure demonstrates the relative stability of the sensor under these experimental conditions.

The histological examination showed a fibrovascular tissular reaction arround the site of implantation of the sensor (Fig. 9a,b). Few inflammatory cells were seen: mainly macrophages, plasma cells and a few polymorphonuclear cells. 

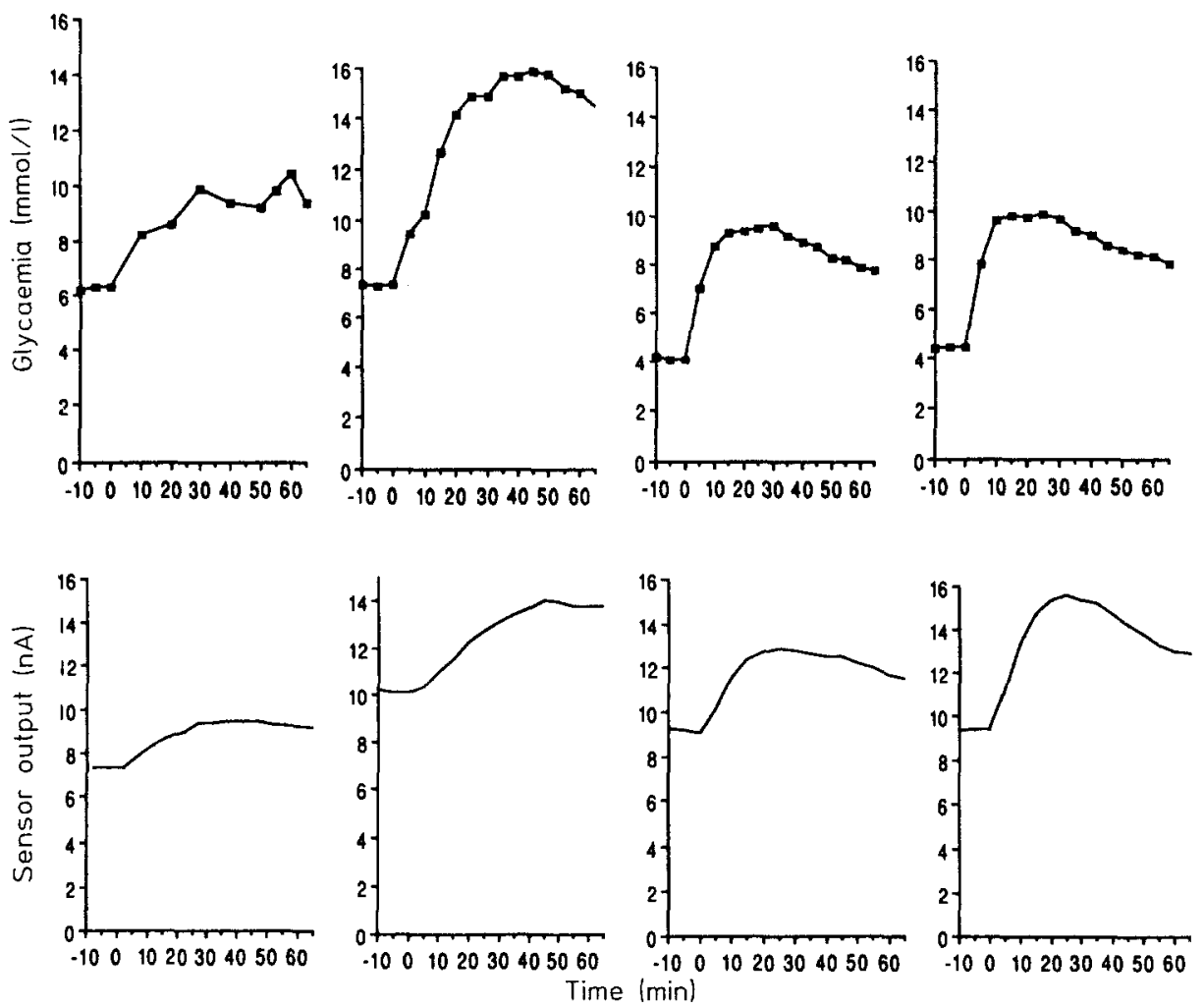

Fig.7. Follow-up study of one sensor implanted for five days in a rat: plasma glucose concentration (upper panel) and concomitant current (lower panel) on days $1,2,3$ and 5 after implantation

\section{Discussion}

This miniaturized glucose sensor was implanted in the subcutanous tissue of normal rats and its ability to monitor glucose concentration was evaluated up to ten days following implantation. This experimental procedure proved to be useful for the long-term assessment of the sensor. It is simple, non-invasive and reproducible. The increase in plasma glucose concentration following an intraperitoneal injection of glucose and the simultaneous changes in subcutaneous glucose concentration were highly reproducible. The kinetics of glucose variation in the subcutaneous tissue - estimated from the changes in the sensor current during the glucose load - were rapid and followed that of blood, even on day 10 , with a lag time always shorter than $5 \mathrm{~min}$. This major finding was clearly demonstrated by using the error grid analysis: on day 3

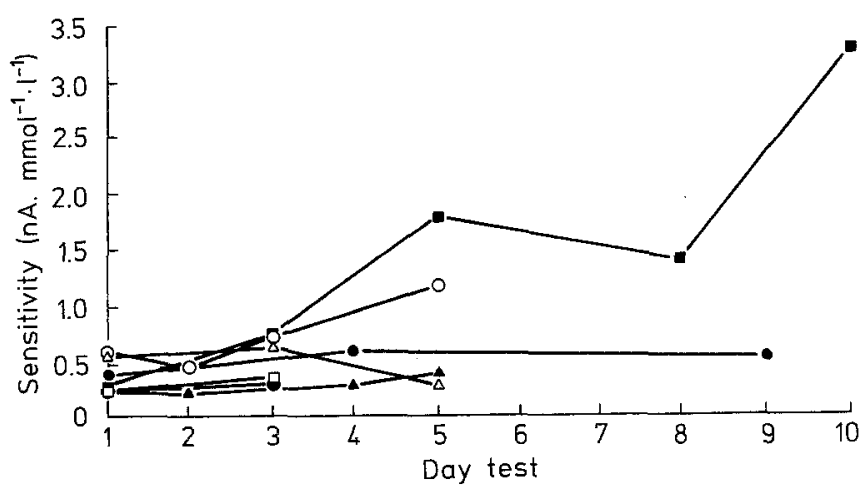

Fig. 8. Longitudinal study of the in vivo sensor sensitivity, up to ten days after implantation $(n=7)$ or 4 , only five out of the 79 estimated values from the signal sensor could have been considered as incorrectly estimated compared with the concomitant plasma glucose concentrations, and on day 10 only one of the 101 estimated values could have been considered as such. Even for these six cases, the values fall within acceptable zone B of the error grid analysis. It is impressive to note that this near-identity between subcutaneous glucose concentration and the concomitant glucose level was observed despite the physiological lag between the changes in plasma glucose concentration and those in the subcutaneous glucose. It is compatible with the use of such a sensor for continuous glucose monitoring and even for its use as a part of a closed-loop insulin delivery system, confirming the interest of subcutaneous tissue as a site for glucose sensing $[12,13]$. We speculate that the tissue reaction observed around the sensor, namely the presence of capillaries could explain the rapid glucose transfer from the blood to the electrode, and thus explain the improved performances with time reported in this paper.

In addition, these data suggest that the sensor developed and evaluated in our laboratories functioned consistently for at least 10 days, which is longer than the duration reported by others, who have consistently observed a drift in the sensitivity within less than 5 days $[17,18]$. The postulated effect was glucose consumption by the surrounding tissue inflammatory response [19].

In contrast, we did not observe a drift in the sensor sensitivity: except for one sensor, the sensitivity determined in vivo remained relatively stable considering that these experiments were performed in anaesthetized animals, which could vary the glucose supply from blood to the sensor. On the other hand, one must consider that the sensors 


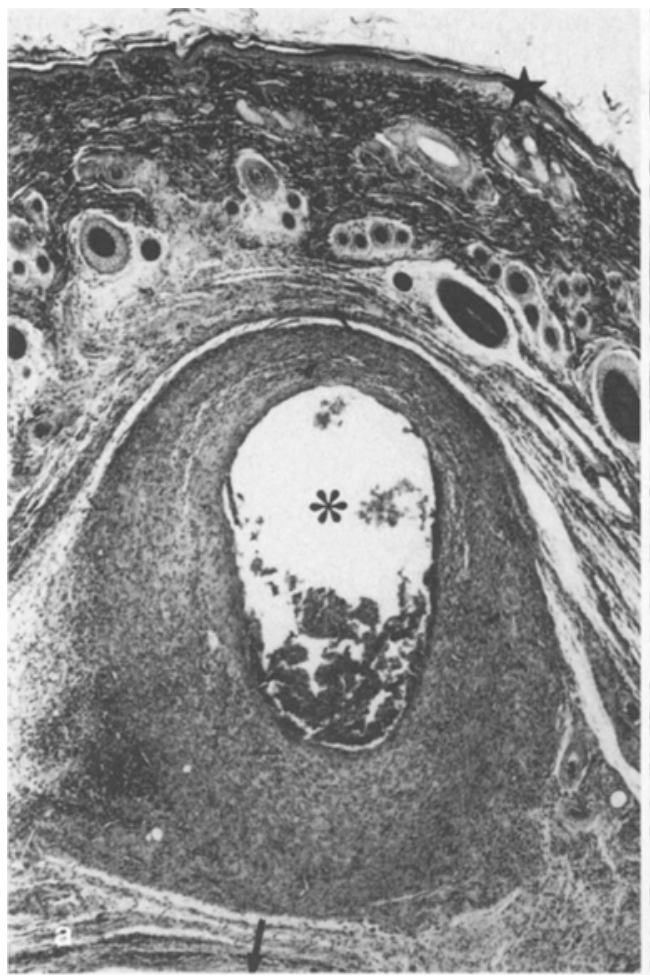

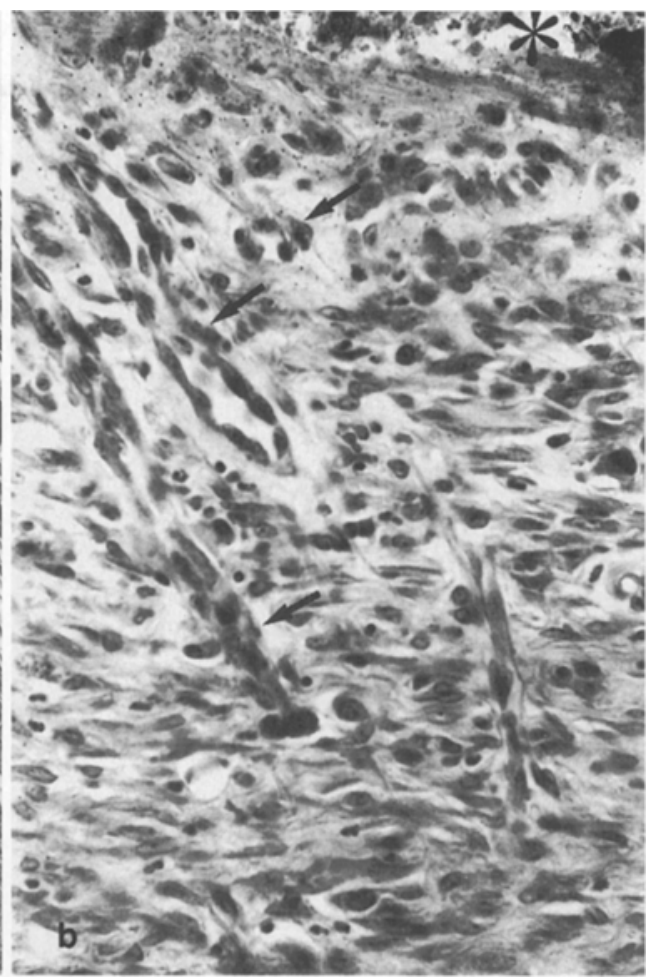

Fig.9. a Transverse section of rat skin and subcutaneous tissue after sensor implantation. A dense granulation tissue surrounds the sensor's area: $\star$ : skin; * : sensor's area; $\rightarrow$ : muscle (haematoxylin and eosin, $\times 40$ ). b Higher magnification of the tissue reaction around the sensor $(*)$, several small capillaries $(\rightarrow)$ are visualized (haematoxylin and eosin, $\times 375)$ were not polarized between the tests. It will be necessary to readdress this issue with a continously polarized sensor. Interestingly, the in vivo sensitivity examined on day 10 (except for one sensor), was identical to that observed on days 3-4 and day 10 for sensors with similar in vitro sensitivity. Although the data were obtained with different groups of sensors and do not represent a longitudinal study, this finding suggests that the in vivo sensitivity in subcutaneous tissue remained stable around $0.5 \mathrm{nA}$. $\mathrm{mmol}^{-1} \cdot 1^{-1}$ between day 3 and day 10 , and are consistent with the data of the longitudinal study.

We observed the development of neovessels around our sensor inside a tissular reaction. It is tempting to speculate that this tissue behaviour was due to the miniaturization of our sensor. In addition, there was no correlation between the in vivo sensitivity and the corresponding in vitro sensitivity of the same sensor (data not shown). This suggests that the in vivo sensitivity is mainly dependent on the in situ environment of the sensor, confirming the need for in vivo calibration.

In conclusion, this paper provides the first evidence that a needle-type glucose sensor miniaturized to a size compatible with clinical use can work for more than 1 week when implanted in rat subcutaneous tissue. The knowledge of the actual duration of the sensor's function is now essential for defining the strategy of its further development, namely towards an implantable or disposable device.

Acknowledgements. We thank Ms. P.Fillatreau for the preparation of the sensors used in this study. This work was supported in part by grants from the National Institutes of Health (DK 30718 to G. Wilson), the Institut National de la Santé et de la Recherche Médicale (CRE 89-90-14 to G. Reach), and l'Aide aux Jeunes Diabétiques.

\section{References}

1. Pickup JC (1985) Biosensors: a clinical perspective. Lancet II: $817-820$

2. Armour JC, Lucisano JY, McKean BD, Gough D (1990) Application of chronic intravascular blood glucose sensor in dogs. Diabetes 39: 1519-1526

3. Shichiri M, Yamasaki Y, Kawamori R, Hakui N, Abe H (1982) Wearable artificial endocrine pancreas with needle-type glucose sensor. Lancet II: 1129-1131

4. Abel P, Müller A, Fischer U (1984) Experience with an implantable glucose sensor as a prerequisite of an artificial beta cell. Biomed Bioch Acta 43: 577-588

5. Matthews DER, Bown E, Bẻck TW et al. (1988) An amperometric needle-type glucose sensor tested in rats and man. Diab Med 5: 248-252

6. Pickup JC, Shaw GW, Claremont DJ (1989) In vivo molecular sensing in diabetes mellitus: an implantable glucose sensor with direct electron transfer. Diabetologia 32: 213-217

7. Claremont DJ, Sambrook IE, Penton C, Pickup JC (1986) Subcutaneous implantation of a ferrocenemediated glucose sensor in pigs. Diabetologia 29: 817-821

8. Kerner W, Bruekel J, Zier H et al. (1989) Glucose measurement in subcutaneous tissue. Artificial Organs 13: 173 (Abstract)

9. Velho GD, Reach G, Thévenot D (1987) The design and development of in vivo glucose sensors for artifical endocrine pancreas. In: Turner APF, Karube I, Wilson GS (eds) Biosensors: fundamentals and applications. Elsevier, Barking, pp 390-408

10. Koudelka M, Rohner-Jeanrenaud F, Terrettaz J, BobbioniHarsch E, de Rooij NF, Jeanrenaud B (1991) In-vivo behaviour of hypodermically implanted microfabricated glucose sensors. Biosensor Bioelectronics 6: 31-36

11. Ege $\mathrm{H}$ (1989) A needle-shaped glucose sensor using an aquaeous polyurethane dispersion for membrane formation and for immobilization of glucose oxidase. Artificial Organs 13:171 (Abstract)

12. Fischer U, Ertle R, Abel P, Rebrin K, Brunstein E, Hahn von Dorsche H, Freyse EJ (1987) Assessment of subcutaneous glucose concentration: validation of the wick technique as a refer- 
ence for implanted electrochemical sensors in normal and diabetic dogs. Diabetologia 30: 940-945

13. Rebrin K, Fischer U, Woedtke TV, Abel P, Brunstein E (1989) Automated feedback control of subcutaneous glucose concentration in diabetic dogs. Diabetologia 32: 573-576

14. Bindra DS, Zhang Y, Wilson $G$ et al. (1991) Design and in vitro studies of a needle-type glucose sensor for subcutaneous monitoring. Anal Chem 63: 1692-1696

15. Velho G, Froguel P, Thévenot DR, Reach G (1989) Strategies for calibrating a subcutaneous glucose sensor. Biomed Biochem Acta 48: 957-964

16. Clarke WL, Cox D, Gonder-Frederick LA, Carter W, Pohl SL (1987) Evaluating clinical accuracy of systems for self-monitoring of blood glucose. Diab Care 5: 622-627

17. Fischer U, Abel P, Rebrin K, Hahn von Dorsche H, Brunstein E (1990) Rôle et possibilités des techniques actuelles de la détermination intracorporelle de la glycémie dans le traitement du diabète insulino-dépendant. Flammarion Médecine-Sciences, Journées de Diabétologie Hôtel-Dieu 1990: 247-366
18. Shichiri M, Kawamori R, Goriya Y, Yamasaki Y, Nomura M, Hakui N, Abe H (1983) Glycaemic control in pancreatectomized dogs with a wearable artificial endocrine pancreas. Diabetologia 24: 179-184

19. Rebrin K, Hahn von Dorsche H (1989) Subcutaneous implanted glucose sensors as a part of the artificial $\beta$-cell. Artificial Organs 13: 174 (Abstract)

Received: 1 August 1991

and in revised form: 4 November 1991

Dr. G. Reach

INSERM U341

Service de Diabétologie

Hôtel-Dieu

1 place du Parvis Notre-Dame

F-75004 Paris

France 